\title{
LA VAGINA DENTADA: UNA INTERPRETACIÓN DE LA ESTELA 25 DE IZAPA Y LAS GUACAMAYAS DEL JUEGO DE PELOTA DE COPÁN
}

\author{
Oswaldo Chinchilla Mazariegos \\ Museo Popol Vuh, Universidad Francisco Marroquín
}

\begin{abstract}
Resumen: Las aves representadas en la Estela 25 de Izapa y el juego de pelota de Copán forman el punto de partida para un examen del tema mitológico de la vagina dentada en Mesoamérica, y sus expresiones en el arte y la narrativa. Un amplio conjunto de narraciones mitológicas recopiladas en México y Guatemala sirve como base para un examen de la historia de Siete Guacamayo en el Popol Vuh, la cual se interpreta como una variante de un mito ampliamente difundido, relacionado con el origen del Sol y la Luna. La identificación de asuntos comunes, entre ellos el de la vagina dentada, refuerza la relación entre el mito del Popol Vuh y las representaciones de Izapa y Copán. A la vez, revela detalles poco conocidos sobre el simbolismo sexual presente en los mitos cosmogónicos mesoamericanos.
\end{abstract}

Palabras clave: vagina dentada, Izapa, juego de pelota, Popol Vuh, Copán.

ABSTRACT: The birds represented at Stela 25 of Izapa and Copan ball court are the starting point for the analysis of the mythological topic focused on the vagina dentata in Ancient Mesoamerica, as well as their expressions on art and narrative. A large body of mythological narratives is used as a basis for the examination of the "Siete Guacamayo" story included in the Popol Vuh, which is interpreted as part of a widely extended myth related with the creation of the Sun and the Moon. The identification of common issues, as the vagina dentata topic, strengthens the links between the Popol Vuh myth and the Izapa and Copan representations. It also reveals less known details on the sexual symbolism included in the Mesoamerican cosmogonic myths.

KeYwords: vagina dentata, ball court, Popol Vuh, Copan.

RECEPCIÓN: 14 de enero de 2010.

ACEPTACIÓN: 28 de junio de 2010. 



\title{
LA VAGINA DENTADA: UNA INTERPRETACIÓN DE LA ESTELA 25 DE IZAPA Y LAS GUACAMAYAS DEL JUEGO DE PELOTA DE COPÁN"
}

\author{
Oswaldo Chinchilla Mazariegos \\ Museo Popol Vuh, Universidad Francisco Marroquín
}

Más que ningún otro monumento, la Estela 25 de Izapa pone de manifiesto la antiguiedad de las creencias mitológicas que, a mediados del siglo xvl, quedaron escritas en el texto que conocemos bajo el nombre de Popol Vuh. A partir de una observación inicial de Gareth Lowe, muchos autores han citado esta estela como una representación preclásica del mito de Siete Guacamayo, el orgulloso personaje que presumía de ser el Sol y la Luna al principio de la creación. Lowe (1982: 297) sugirió que la estela podría representar el pasaje donde Siete Guacamayo cercenó el brazo de Hunahpu, al observar el muñón sangrante del protagonista. Con el brazo que le queda, éste sostiene un armazón sobre el cual se posa un gran pájaro con las alas abiertas. El brazo cercenado del héroe aparece en el vientre del pájaro, que posee fauces propias, de aspecto serpentino. Estas fauces sujetan el brazo, cuya mano cuelga hacia afuera (figuras 1-4). ${ }^{1}$

El tema se repitió, algunos siglos más tarde, en las grandes guacamayas de estuco, descubiertas por William y Bárbara Fash (1996, 2000; Fash, 1998) en la

\footnotetext{
* Esta investigación fue posible gracias al apoyo institucional del Museo Popol Vuh de la Universidad Francisco Marroquín. Por su generosa colaboración, agradezco especialmente a Hernando Gómez Rueda, cuyas fotografías de la Estela 25 de Izapa permiten entender los detalles del monumento mejor que ningún registro anterior. Con gran generosidad Valentina Glockner Fagetti me permitió citar su trabajo etnográfico inédito. Gracias a la amable atención de Félix Báez-Jorge, tuve acceso a sus valiosos textos sobre el tema. Este trabajo se ha beneficiado significativamente de las observaciones iconográficas de Karl Taube, y de los comentarios de Félix Báez-Jorge, Carlos Navarrete y Liwy Grazioso. Agradezco también a Bárbara Fash por su autorización para reproducir los dibujos de las guacamayas de Copán. Sobra decir que las ideas vertidas en este trabajo son responsabilidad del autor.

${ }^{1}$ El dibujo que se presenta en las figuras 1 y 2 está basado en una fotografía de alta calidad, y fue realizada por Hernando Gómez Rueda. Las fauces ventrales del pájaro también se aprecian en el dibujo punteado realizado por Ramiro Jiménez del Pozo y Máximo Prado para la New World Archaeological Foundation, que se reproduce en la figura 4. No así en el dibujo de V. Garth Norman (1973), ni en el de Ayax Moreno (Clark y Moreno, 2007). Este último presenta una versión muy imprecisa del brazo y las fauces que lo sujetan. A pesar de su estado de conservación relativamente bueno, el relieve de la estela ha sido difícil de entender (Grazioso Sierra, 2002). Algunos detalles sufrieron daños cuando la estela fue robada, entre 1960 y 1962 (Norman, 1976: 132; Carlos Navarrete, comunicación personal, 2009).
} 


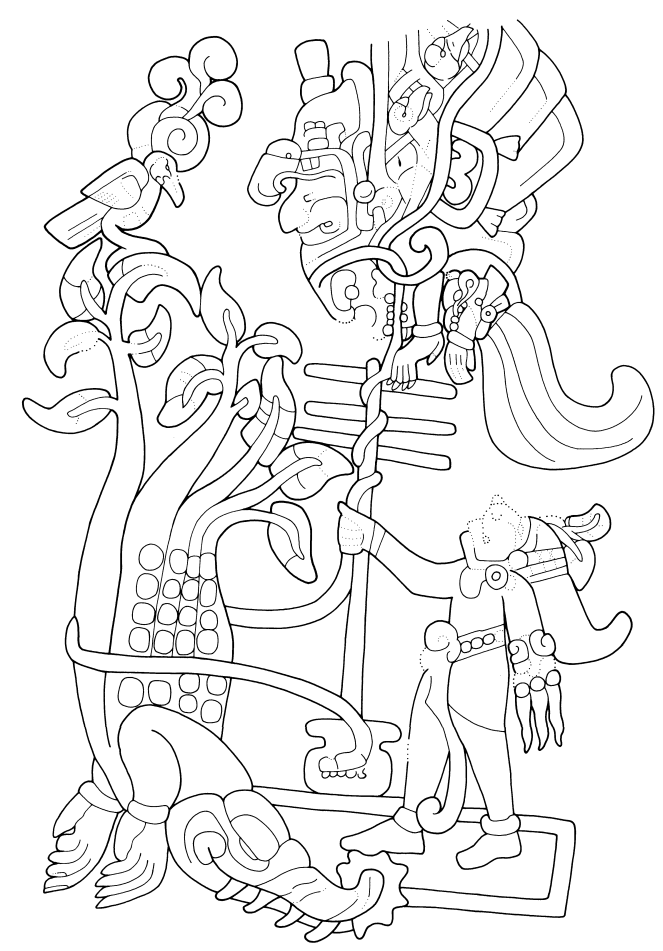

Figura 1. Estela 25 de Izapa.

Dibujo: Oswaldo Chinchilla

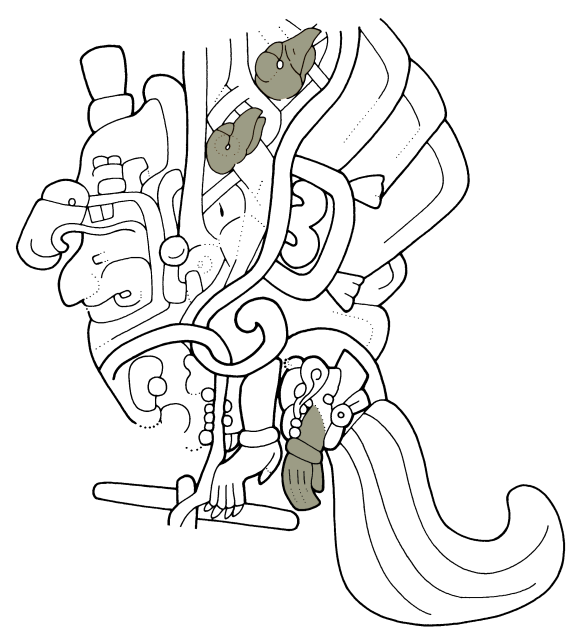

Figura 2. Detalle de la Estela 25 de Izapa, con indicación de los elementos iconográficos que se describen en el texto. Dibujo: Oswaldo Chinchilla 


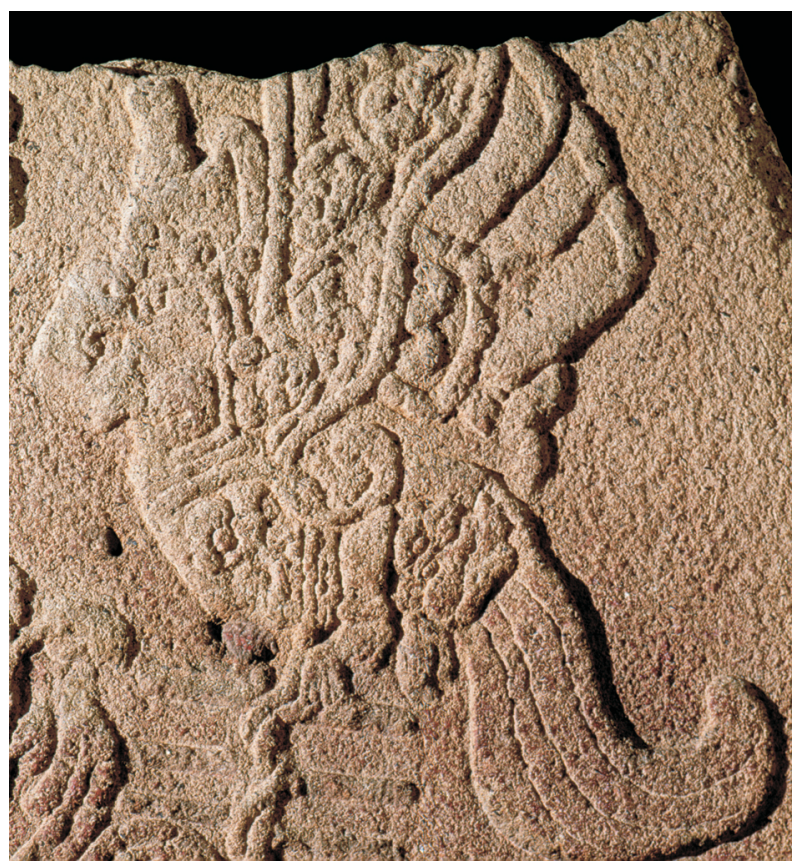

Figura 3. Detalle de la Estela 25 de Izapa.

Foto: Hernando Gómez Rueda

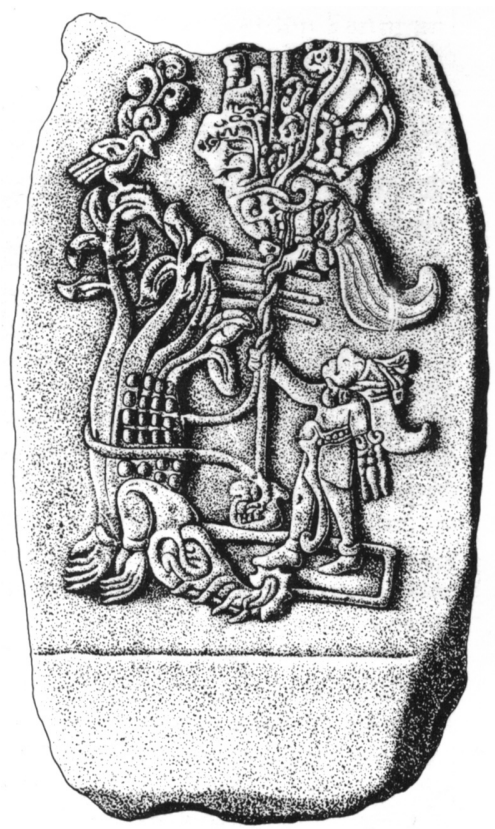

Figura 4. Estela 25 de Izapa. Dibujo de Ramiro Jiménez del Pozo y Máximo Prado, New World Archaeological Foundation. Obsérvense las fauces serpentinas en el vientre del pájaro, que sujetan el brazo cercenado 
primera versión del juego de pelota de Copán (figuras 5-6). Del abdomen de estas aves emerge la cabeza de una serpiente emplumada, que sujeta entre sus fauces un brazo cercenado. Un detalle crucial es la marca de forma oval en el brazo, que los Fash reconocieron como una de las manchas que caracterizan la piel del dios joven con la piel manchada, designado como Dios S por Taube (1992). Michael Coe lo reconoció hace varias décadas como una manifestación de Hunahpu, el héroe solar del Popol Vuh, que perdió un brazo luchando contra Siete Guacamayo. Como la Estela 25 de Izapa, este relieve parece derivarse de una versión del mito, en la que el pájaro no arrancó el brazo del héroe con el pico, sino con las fauces monstruosas de su vientre.

En las páginas que siguen, las aves de Izapa y Copán sirven como puntos de partida para una discusión sobre el mito de Siete Guacamayo. La comparación del relato del Popol Vuh con otras narraciones permite entenderlo como una versión de un pasaje muy difundido en la mitología mesoamericana, sobre la derrota de un monstruo, con figura de ave o serpiente, que pretendía ser el Sol o que ocultaba el Sol con sus alas. La muerte de este monstruo fue un paso indispensable para el advenimiento del Sol y la Luna. En algunos relatos, la derrota de este ser corre parejas con la de una mujer que, según las versiones más explícitas, poseía una vagina dentada. La interpretación de las fauces ventrales de las aves de Izapa y Copán como vaginas dentadas abre una puerta para entender las connotaciones sexuales del mito, presentes tanto en las representaciones prehispánicas como en el relato del Popol Vuh. Las alusiones al tema mitológico de la vagina dentata refuerzan la relación de la Estela 25 de Izapa con el texto k'iche' del siglo xvi; ambas se derivan de mitos estrechamente relacionados que han permanecido vigentes por miles de años en el pensamiento religioso mesoamericano.

\section{La derrota del falso Sol}

En el Popol Vuh, Siete Guacamayo era un ser primigenio, que pretendía ser el Sol y la Luna, y presumía de sus riquezas, del brillo de su plumaje, sus dientes y sus ojos.

Yo soy grande. Habito sobre las cabezas de la gente que ha sido formada y modelada. Soy su Sol. También soy su luz. Y también soy su Luna. Que así sea. Grande es mi brillo. Por el brillo de mi plata y mi oro ilumino los senderos y caminos de la gente. Mis ojos brillan con resplandecientes joyas verdes/azules. Mis dientes también son piedras de jade, tan brillantes como la faz del cielo. Este, mi pico, resplandece luminosamente en la distancia, como la Luna (Christenson, 2003: 92). ${ }^{2}$

A pesar de sus desplantes, el Popol Vuh afirma que esto sucedía "mientras la faz de la tierra estaba iluminada sólo un poco" (Christenson, 2003: 91). El brillo de

${ }^{2}$ Todas las traducciones del inglés al español son responsabilidad del autor de este artículo. 


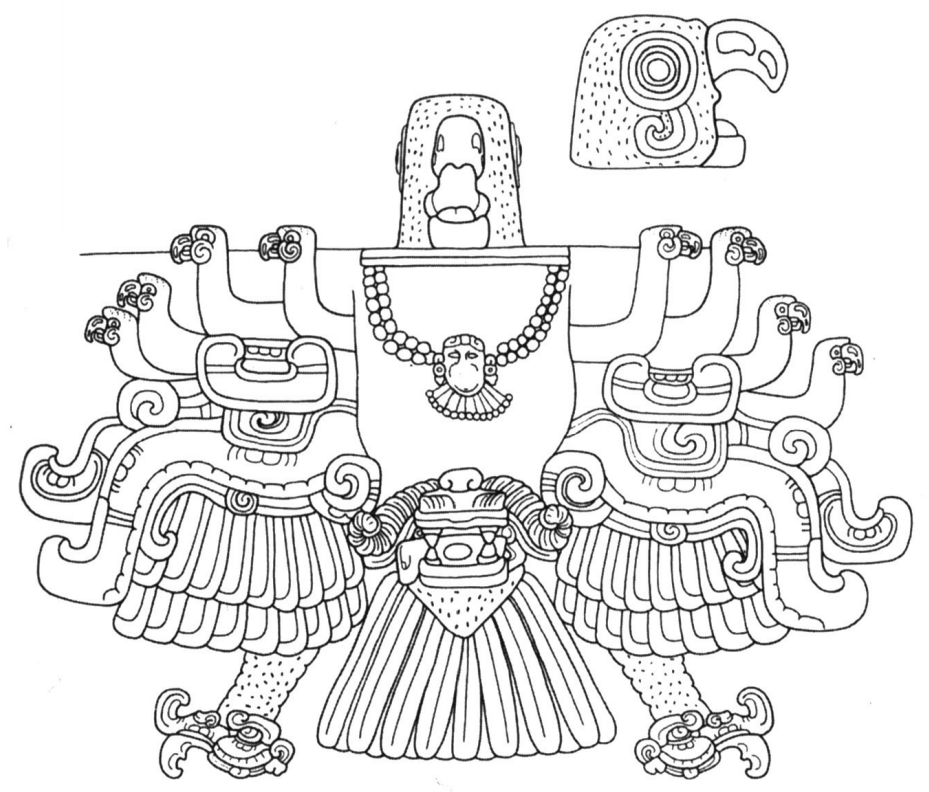

Figura 5. Guacamaya de estuco del primer juego de pelota de Copán. Dibujo de Bárbara Fash, Proyecto de los Mosaicos de Copán e Instituto Hondureño de Antropología e Historia

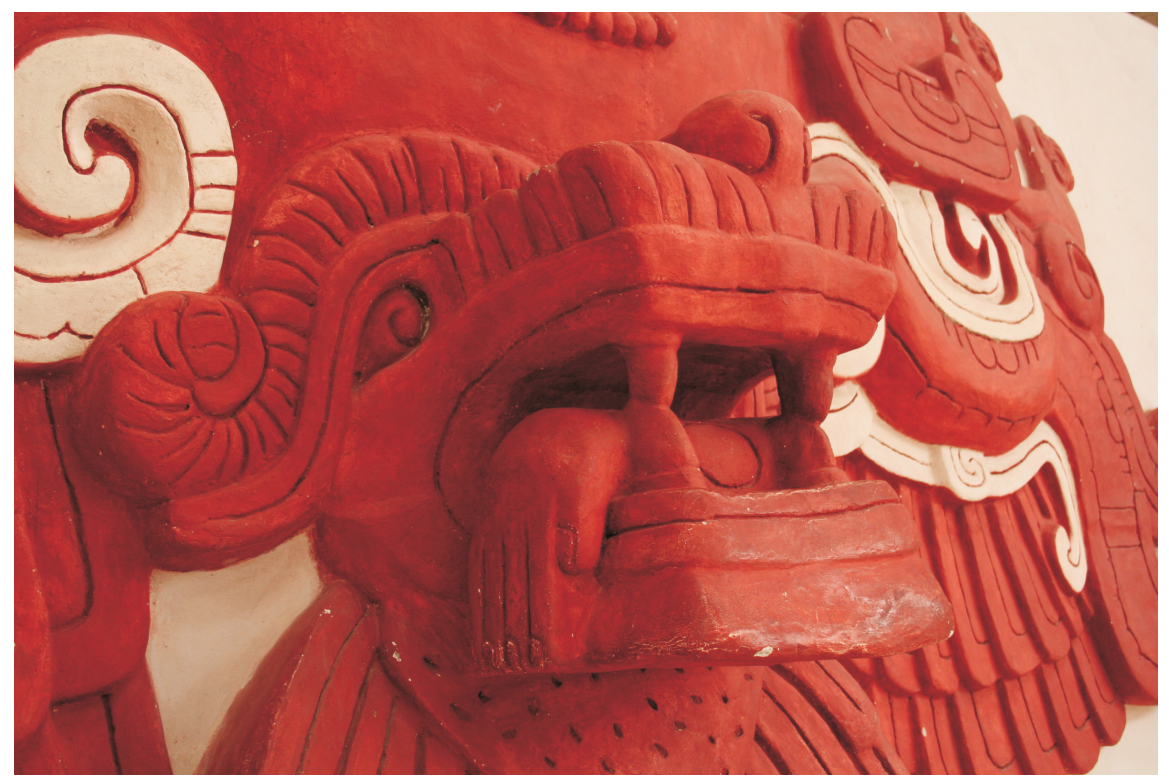

Figura 6. Detalle de guacamaya de estuco del primer juego de pelota de Copán, que muestra el brazo cercenado en las fauces de la serpiente emplumada en el vientre de la guacamaya. Réplica en el Museo de las Esculturas de Copán. Foto: Oswaldo Chinchilla 
Siete Guacamayo era insuficiente para alumbrar el mundo. Los Héroes Gemelos se aprestaron a vencerlo, y lo esperaron cuando subía a comer nances en un árbol. Hunahpu le disparó con su cerbatana y acertó a darle en la mandíbula, causándole un gran dolor de dientes; pero en la lucha, Siete Guacamayo consiguió arrancarle un brazo. Los héroes hicieron creer a Siete Guacamayo que podían curar su dolor, pero en vez de eso le sacaron los dientes y los ojos, quitándole así el resplandor del que se enorgullecía. Al morir Siete Guacamayo, murió también su esposa, de quien sólo sabemos el nombre: Chimalmat (Christenson, 2003: 91-100).

La derrota de Siete Guacamayo en el Popol Vuh ha sido interpretada como la destrucción de un falso Sol, o el de una era anterior, indispensable para el advenimiento del nuevo Sol, lo cual finalmente ocurrió por medio de la apoteosis de los Héroes Gemelos como Sol y Luna (cf. Krickeberg, 1971: 237; Graulich, 1997: 135-141; Christenson, 2003: 91-92). En efecto, hay pasajes paralelos en numerosos relatos que narran la derrota de un gran pájaro o un monstruo esencialmente análogo por parte de los héroes que habrían de convertirse en Sol y Luna. Estos relatos son abundantes en Oaxaca, y también se han recopilado en comunidades indígenas de Guerrero, Puebla, Veracruz y San Luis Potosí.

Julia Guernsey y Gustavo Torres Cisneros han relacionado el mito k'iche' con los relatos mixes de Oaxaca, que narran la historia de dos hermanitos — niño y niña- que habrían de convertirse en el Sol y la Luna (Guernsey, 2006: 112; Torres Cisneros, 2007: 366-370). Según una versión recopilada por Walter Miller, el monstruo era una gran culebra que comía gente, pero otras narraciones mixes simplemente hablan de un gran animal que se llevó a los niños mientras dormían, dejándolos en lo alto de un peñasco o de un árbol (Miller, 1956: 92; Hoogshagen, 1971: 345; Lipp, 1991: 75). Las versiones recopiladas entre los nahuas de Veracruz, los chatinos y triques de Oaxaca, y los tlapanecas de Guerrero, presentan a los gemelos como dos varones que vencieron a una culebra que tenía los ojos muy brillantes, o a un animal grande que comía gente (De Cicco y Horcasitas, 1962; Hollenbach, 1977: 142-143; Bartolomé, 1979: 25; Van der Loo, 2002: 76; Oropeza Escobar, 2007: 214-223; Villela Flores, 2008). Para matarlo, los héroes lo flecharon o le arrojaron piedras calientes en la boca. Un detalle crucial, ausente en las versiones mixes, es el momento en que los héroes arrancan los ojos del animal muerto. El mito explica cómo el Sol logró quedarse con el ojo derecho, más brillante, mientras que el izquierdo le quedó a la Luna. Con ellos alumbran desde el cielo.

Un paralelo más cercano para el relato del Popol Vuh se encuentra en las versiones mazatecas y chinantecas del mito, donde el monstruo era un águila con varias cabezas (Boege, 1984; Portal, 1986: 51-52; Carrasco y Weitlaner, 1952: 172; Weitlaner y Castro, 1973: 200; Weitlaner, 1981: 54-55; Zaragoza, 2007). Según la versión chinanteca de Marcelino Mendoza, publicada por Roberto Weitlaner, los héroes debieron aguardar hasta las doce del día, la hora en que el ave dormía. En ese momento, le amarraron una cuerda al pescuezo y jalaron hasta sacarle 
los ojos, con lo que murió. Como en otras narraciones, los héroes recogieron los ojos y el Sol se quedó con el derecho, que brillaba como el oro. La extracción de los ojos es crucial en los mitos de Oaxaca y Guerrero; aquellos eran el origen del brillo del falso Sol, y luego se convirtieron en la fuente del resplandor del nuevo Sol y la nueva Luna. Este detalle está ausente en el Popol Vuh, pero aún así el texto se detiene a describir cómo los héroes sacaron los ojos de Siete Guacamayo, que resplandecían como metales preciosos: "Entonces los ojos de Siete Guacamayo fueron curados. Sus ojos fueron arrancados, removiendo completamente el metal precioso de ellos" (Christenson, 2003: 100).

La muerte del ave a las doce del día es un detalle trascendental, que se repite en otras narraciones y alude claramente al curso solar. La hora también es importante en una narración popoloca del sur de Puebla, según la cual el ave estaba sentada frente al Sol, oscureciendo la tierra. El héroe la mató de un flechazo, temprano por la mañana, con lo cual el mundo se aclaró. El responsable fue un ser montaraz, el "hombre animal" u "hombre nacido del monte", característica que lo aproxima a los héroes del Popol Vuh (Jäcklein, 1974: 276). En cambio, entre los teenek y los nahuas de San Luis Potosí fue el héroe del maíz quien venció al gran pájaro, un águila o un gavilán. En la versión teenek, el monstruo llegaba justo a mediodía para devorar a sus víctimas, tapando los rayos solares al volar. Apropiadamente, el héroe preparó una gran olla de atol de maíz y, mediante una treta, consiguió que el gavilán se parara en el palo movedor que estaba encima de la olla. En ese momento, el héroe quitó el palo y el monstruo cayó dentro del atol hirviendo, donde la gente lo remató a golpes. Se sorprendieron al ver que de cada pluma que le arrancaban salía volando un gavilancito (Ochoa Peralta, 2000; Castellón Huerta, 1987: 191).

\section{De guacamayas y brazos cercenados}

El ave de múltiples cabezas del mito chinanteca y el gavilán de los teenek, cuyas plumas generaban gavilancitos, tienen largas raíces en la mitología de Mesoamérica. Nuevamente, la Estela 25 de Izapa ofrece el testimonio más antiguo. En el ala desplegada del gran pájaro se pueden observar por lo menos dos y quizá tres cabezas de pájaros, que se asoman entre las bandas entrelazadas que llenan la mitad superior del ala (figura 2). Como en los relatos contemporáneos, parecen nacer de las alas del pájaro monstruoso.

Las cabezas de ave que nacen en sus alas refuerzan el paralelismo del pájaro de la Estela 25 con las guacamayas de estuco del juego de pelota de Copán. Taube (2005: 40-43) ha identificado otras representaciones relacionadas en los murales de Teotihuacán, en los incensarios y efigies de Escuintla y en una columna labrada de El Tajín, que representan guacamayas con múltiples cabezas en las alas (figuras 7-9). Taube las interpretó a la luz de una creencia recopilada por Robert Zingg entre los huicholes, según la cual los loros y las guacamayas son 
a)

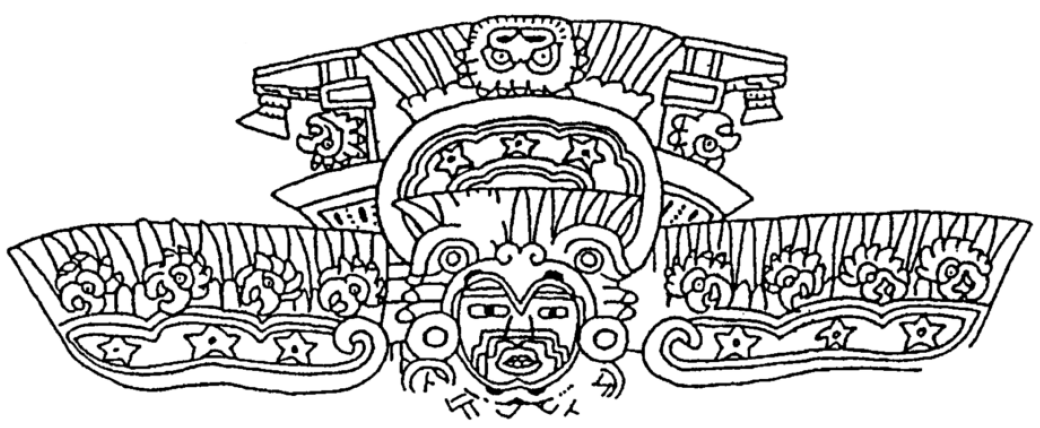

b)

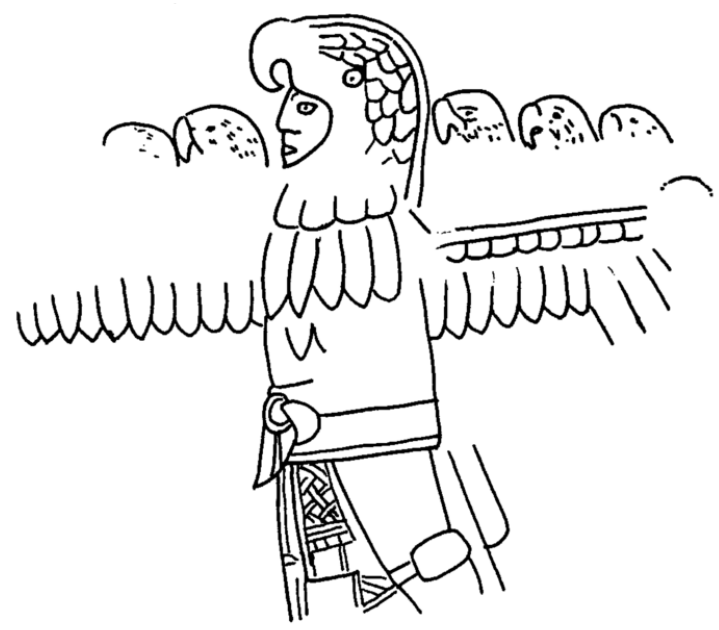

Figura 7. Guacamayas con múltiples cabecitas en las alas. (a) Mural de la Zona 5A de Teotihuacán; (b) Edificio de las Columnas, El Tajín. Dibujos por Karl Taube

los animales del Sol. La guacamaya anunció el primer amanecer y, cuando agitó sus alas, muchos loros pequeños volaron hacia las cinco direcciones del mundo (Zingg, 1982, vol. 1: 512; vol. 2: 188). Aunque el relato huichol no implica la muerte de la guacamaya, es claro que esta ave, relacionada con el Sol, es contraparte del gran gavilán del relato teenek, de cuyas plumas nacían gavilancitos.

En el arte prehispánico, las aves con múltiples cabezas en las alas se asocian repetidamente con brazos cercenados. Se encuentran ejemplos en los incensarios de estilo teotihuacano, de Escuintla, que representan templos dedicados al culto del pájaro monstruoso (figura 8). En los dos ejemplos conocidos, el techo del templo está dominado por grandes guacamayas con rostros humanos en el pico, y cabecitas adicionales en las alas extendidas. Tal parece que las grandes guacamayas de los templos de Escuintla compartían las costumbres de Siete Guacamayo en el Popol Vuh, a juzgar por las hileras de brazos cercenados que cuelgan en el techo de los templos, amarrados con sendas cuerdas. Las gotas de 


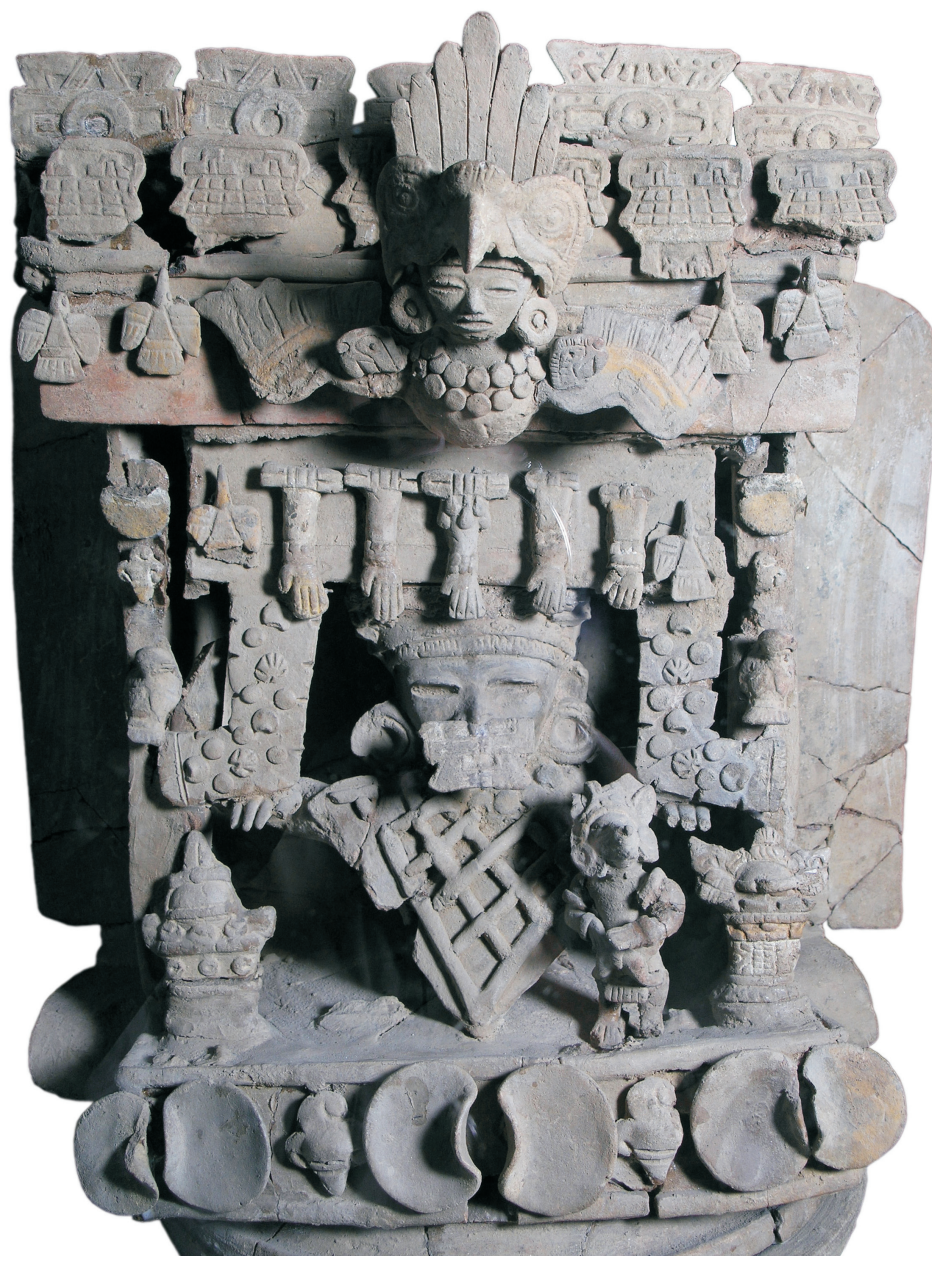

Figura 8. Incensario de estilo teotihuacano, procedente de Escuintla. Colección del Banco Industrial, Guatemala. Obsérvese la guacamaya con cabecitas en las alas, y los brazos cercenados que cuelgan del techo del templo. Foto: Mauricio Acevedo.

sangre que manan del brazo que ocupa la posición central, bajo el ave, revelan su reciente corte. ${ }^{3}$

Los brazos colgantes hacen recordar el destino del brazo de Hunahpu en el Popol Vuh, donde Siete Guacamayo le dijo a Chimalmat: "Esto lo he traído para colgarlo sobre el fuego. Se mecerá sobre el fuego hasta que vengan a recogerlo"

${ }^{3}$ Uno de estos incensarios se encuentra en la colección del Banco Industrial, ciudad de Guatemala (figura 8). El otro fue fotografiado por Justin Kerr, y corresponde al número 8037 en A Pre-Columbian Portfolio < http://www.mayavase.com > . [Consultada el 14 de enero de 2010.] 


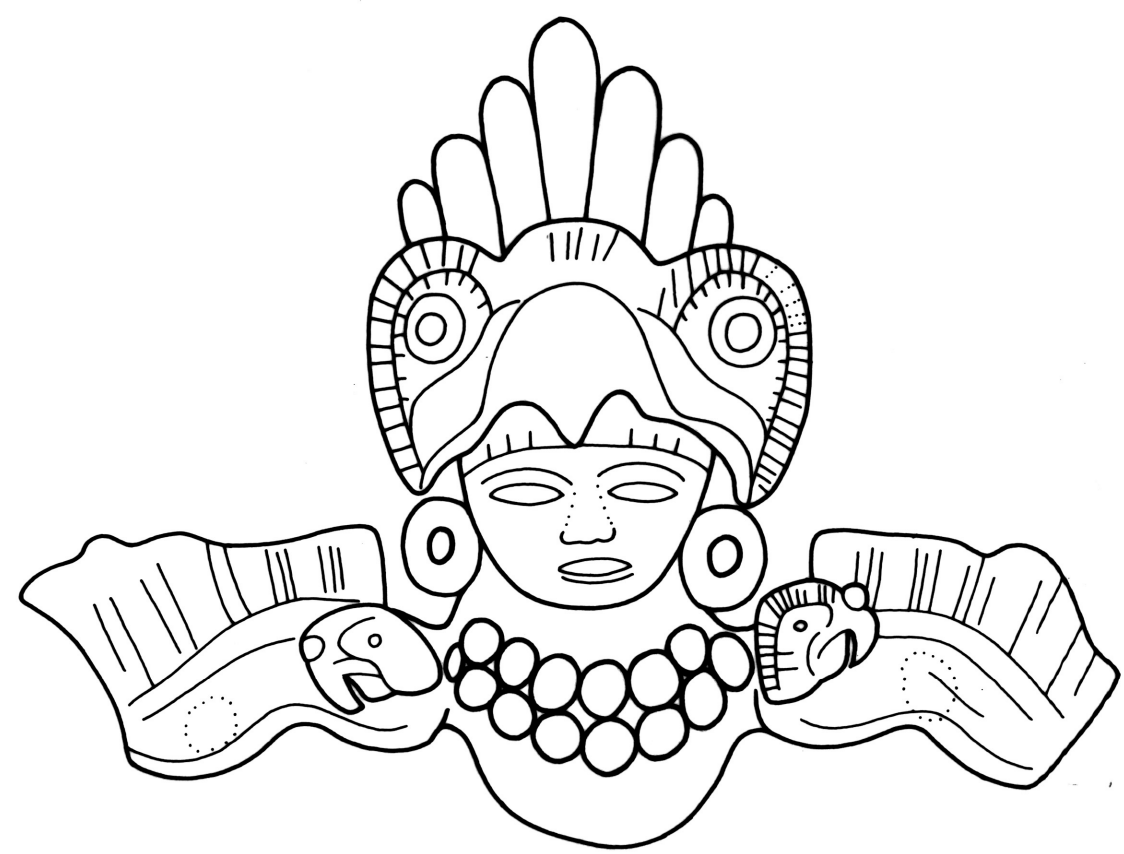

Figura 9. Guacamaya con pequeñas cabezas que nacen en las alas. Las áreas punteadas corresponden a los puntos donde faltan otras cabecitas similares. Detalle del incensario representado en la figura 7. Dibujo del autor

(Christenson, 2003: 97-98). No hay razón para dudar que el culto del gran pájaro en los templos de Escuintla exigiera ofrendas de brazos cercenados. En uno de estos incensarios, los brazos se mecen sobre el fuego que arde en dos pebeteros colocados a las puertas del templo (figura 8).

El culto del gran pájaro solar no fue exclusivo de los templos de Escuintla. En la época de la conquista española, el templo principal de Izamal, en Yucatán, estaba dedicado a K'inich K'ahk Mo', cuyo nombre significa, literalmente "Rostro (u ojos) de Sol, guacamaya de fuego". Varios autores (v.g. Girard, 1972: 61; Christenson, 2003: 91) han asociado esta deidad con la figura de Siete Guacamayo en el Popol Vuh. Como los pájaros solares de los mitos chinantecas y teenek, K'inich K'ahk Mo' bajaba al mediodía a quemar con su fuego los sacrificios que se le ofrecían en el templo de Izamal (Lizana, 1988: 56).

En sus comentarios a las guacamayas de Copán, Fash y Fash $(1996,2000)$ identificaron las fauces en el vientre de estas aves como serpientes emplumadas de estilo teotihuacano, y las relacionaron con la persona de K'inich Yax K'uk' Mo', el fundador de la dinastía real de Copán. Taube $(2005,2006: 165)$ ha reiterado esta asociación, y relaciona las guacamayas de Copán y Escuintla con las aves portentosas representadas en los murales de la Zona 5A de Teotihua- 
cán (figura 7a), en las que detecta rasgos estilísticos de probable origen maya. Considerando la posición geográfica de Copán, Taube sugiere que las aves de Teotihuacán pueden evocar al propio K'inich Yax K'uk' Mo' como personificación del Sol naciente en el oriente. Sin embargo, la Estela 25 de Izapa revela que, tanto las avecitas que nacen en las alas de estos pájaros, como sus fauces ventrales, formaban parte de creencias arraigadas en el sur de Mesoamérica desde el periodo Preclásico. De ser correcta, la identificación de las guacamayas de Copán —y posiblemente las de Teotihuacán- con K'inich Yax K'uk' Mo', debería entenderse como resultado de la adopción de un tema mitológico antiguo y ampliamente conocido en el sur de Mesoamérica, como modelo para la glorificación del fundador de la dinastía de Copán.

\section{La vagina dentada}

¿Cómo explicar las fauces serpentinas en el vientre de la gran guacamaya de Copán, seguramente análogas a las que muerden el brazo cercenado en la Estela 25 de Izapa? Su posición en el vientre de los pájaros es una de las razones que conducen a relacionarlas con la vagina dentata, un tema mitológico que se repite en múltiples formas a lo largo del continente americano, y que también se encuentra muy extendido en el área circumpacífica (Berezkin, s.f.). Esencialmente, los mitos expresan la creencia en mujeres terribles con dientes en la vagina, las cuales devoran el miembro genital de los hombres que intentan copular con ellas y, según algunas versiones, los matan. Con frecuencia, los héroes logran remover los dientes vaginales utilizando un pene de piedra u otro material duro como bambú, hueso o cuerno de venado, mediante lo cual permiten las relaciones sexuales. En ocasiones, la historia termina con la muerte de las ogresas (v.g. Malotki, 1983).

El reciente libro de Félix Báez-Jorge, El lugar de la captura, ofrece un análisis extenso de las creencias relacionadas con la vagina dentada en Mesoamérica. Tales creencias se han reportado entre los huicholes, otomíes, mazahuas, mixtecas, huaves y zoques. Algunas versiones huicholes involucran al héroe Kauyumari o Kauymali, quien se colocó un cuerno de venado para romper las dentaduras vaginales (Zingg, 1982, vol. 1: 22; Benítez, 1984: 446-449; Báez-Jorge, 1996). Según otra narración, Kauyumari encontró un peyote que era una mujer. Al copular con ella, "fue devorado por la barranca" (Gutiérrez del Ángel, 2007: 80), destino que alude al simbolismo telúrico, frecuentemente asociado con las ogresas provistas con dientes vaginales. Neurath (2004) reporta otra creencia huichol, según la cual el Sol es seducido por la serpiente del inframundo, que se le aparece con forma de sirena o muchacha con cola de serpiente, al comienzo de las lluvias, durante el solsticio de verano. Al copular con ella, el Sol es devorado por su vagina dentada y se transforma en su alter ego, el Sol nocturno.

En algunos relatos recopilados en Guerrero y Oaxaca, la derrota de las ogresas con vaginas dentadas está directamente relacionada con los mitos de origen del 
Sol y la Luna. Un mito mixteca reitera el episodio, ya conocido, en el que los gemelos que habrían de convertirse en el Sol y la Luna mataron a una serpiente de siete cabezas que exigía víctimas humanas, y se quedaron con sus ojos (Villela Flores, 2008: 6). A continuación, los héroes lograron dormir a la dueña de la serpiente, quien estaba armada con dientes en la vagina. El hermano menor, que habría de convertirse en Luna, le rompió los dientes con una tenaza y logró copular con ella. Según otra versión, utilizó una mano de moler para romper los dientes vaginales de la mujer. ${ }^{4}$ Otras versiones no afirman que tuviese dientes en la vagina, pero hay detalles que lo sugieren. Como los héroes que quitan a las ogresas sus dientes vaginales, los protagonistas de un relato trique se colocaron piedras en el pene para violar a una vieja (Hollenbach, 1977: 144). Según diferentes narradores, usaron una piedra de cuchillo (posiblemente pedernal), una piedra de cal o una piedra de las que se usan para moler chile. El uso de un instrumento para remover los dientes vaginales reaparece en las creencias huaves y mazahuas (Lupo, 2002; Millán, 2007: 161; Galinier, 1990a: 260).

En estos relatos, la figura del monstruo solar se traslapa con la de la vieja - a veces su abuela - que recogió al héroe o héroes huérfanos, pero que más adelante buscó destruirlos. Un mito nahua enfatiza el hecho de que el monstruo - una culebra que comía gente- murió justo al momento en que los héroes encerraron a la abuela en un temascal, matándola (Oropeza Escobar, 2007: 214223). Según un mito zapoteca, el monstruo de ojos brillantes era un hermano de la vieja (Parsons, 1936: 324-326) y un relato tlapaneca afirma que la vieja deseaba convertirse en el Sol o la Luna, detalle que la aproxima considerablemente a la personalidad de Siete Guacamayo en el Popol Vuh (Van der Loo, 2002: 76).

La vagina dentada puede adoptar la forma de una serpiente. Báez-Jorge ha documentado las creencias zoques relacionadas con la Nawayomo, una serpiente monstruosa que se transforma en mujer para seducir a los hombres, cuya vagina es la boca de una culebra:

Hay una culebra en los arroyos, es grande como mazacoate. Es la culebra que se vuelve Nawayomo [...] es mujer pero su cosa [órgano genital] es la boca de una culebra; los muchachos no saben y la siguen. Por eso se mueren de hemorragia, porque los muerde cuando la usan [copulan]; salen en las noches (Báez-Jorge, 1990: 10).

De modo parecido, un relato mixteca narra cómo un hombre se enamoró perdidamente de una mujer, pero después de haber copulado con ella descubrió, horrorizado, que su vagina era la boca de una serpiente. Poco después murió (Monaghan, 1995: 145).

Los relatos mitológicos del área maya son menos explícitos, pero no faltan alusiones a temas relacionados con las vaginas dentadas. Según una narración kaqchikel, recogida en San Antonio Palopó, los héroes usaron una caña para qui-

${ }^{4}$ Valentina Glockner Fagetti, Proyecto de Etnografía de los Pueblos Indígenas de México en el Nuevo Milenio, Instituto Nacional de Antropología e Historia, comunicación personal, 2010. 
tarle la vulva a su abuela, a partir de la cual crearon el guiisquil (Redfield, 1946: 254). En los mitos ch'orti's, la vieja se quebró los dientes al morder (con la boca) una mano de moler, que el héroe había puesto en su cama, a sabiendas de que ella se estaba afilando los dientes para devorarlo (Fought, 1989; López García, 2002, vol. 2: 17-18). Lo mismo sucede en un relato tzotzil, donde el héroe se puso duro como una piedra de las que se hacen metates. Al día siguiente, la vieja se quejaba: “iAh, duelen todos mis dientes!” (Guiteras Holmes, 1996: 153; Arias, 1990: 31). La ruptura de los dientes con un instrumento duro, de forma fálica, replica el procedimiento empleado para despojar a las ogresas de sus dientes vaginales en numerosas narraciones, dentro y fuera del área cultural mesoamericana.

Las creencias, ampliamente difundidas, en seres con vagina dentada — que a veces toma forma de serpiente- ofrecen una base para interpretar las fauces serpentinas que aparecen en el vientre de los pájaros representados en Izapa y en Copán como vaginas dentadas. El paralelismo se completa al considerar los brazos cercenados. Cecelia Klein (2001: 211, 234-235) ha señalado que la pérdida de un miembro del cuerpo, especialmente un pie, se asocia en Mesoamérica con la sexualidad ilícita o deshonesta, y los héroes o dioses que se caracterizan por su cojera suelen ser transgresores sexuales. Entre ellos se encuentra el héroe huichol Kauyumari, y también el dios tz’utujil Mam, que perdió su pie izquierdo, su mano izquierda, o a veces su dedo izquierdo — dependiendo del narradordurante su lucha contra Itziil Winaq, "mala persona”. Este monstruo exigía el sacrificio de mujeres jóvenes, a quienes consumía dentro de la cueva en la que vivía, en lo alto del volcán. Mam lo destruyó por medio del rayo, pero en la lucha, perdió un miembro, que fue a parar al fondo del lago de Atitlán. La sexualidad irrefrenable, e incluso la ambiguiedad sexual, son características importantes de Mam (Mendelson, 1965: 128-135; Tarn y Prechtel, 1997: 74-83; Stanzione, 2003: 57-58; Klein, 2001: 211-219).

El monstruo en el volcán encuentra un paralelo en la Piowačwe, que vive en el volcán Chichón, según una creencia zoque documentada por Báez-Jorge (1983: 393-394). La ogresa quiso seducir a un héroe, que la evitó al saber que tenía dientes en la vagina. La Piowačwe se enojó, se convirtió en volcán, y hace temblar la tierra cuando está enojada. Por otro lado, Itziil Winaq es análogo a los monstruos solares de los mitos recopilados en diversas regiones de México, que como él exigían víctimas humanas.

En las versiones del mito tz'utujil reportadas por Stanzione, la pérdida de cualquier miembro del cuerpo parece ser indistinta. Del mismo modo, en sus estudios sobre la lengua y la religión otomí y mazahua, Jacques Galinier (1984, 1990a: 627633 ; 1990b: 261; 2001) ha observado una analogía estructural entre la pérdida o ausencia de un miembro del cuerpo — un brazo, una pierna o incluso la cabezaque forma parte de un complejo de ideas ligado a la castración. La relación sexual se concibe como un sacrificio, en el que la mujer consume el órgano sexual masculino ( $c f$. Sahlins, 1987: 55, para una creencia similar entre los maoríes). El brazo 
o la pierna cercenados son equivalentes simbólicos del pene en esta concepción, relacionada con las creencias en seres con vagina dentada. Entre las figuras de papel recortado utilizadas en los rituales otomíes, Galinier describe el "aire sin pie", el "hombre sin brazo" y el "hombre sin cabeza", que poseen propiedades esencialmente idénticas, y se caracterizan por su potencia sexual.

Desde esta perspectiva, se explica la presencia del brazo cercenado del héroe, no en el pico, sino en las fauces ventrales - la vagina dentada - de los pájaros monstruosos de Izapa y Copán. El brazo es un símbolo fálico, que ha penetrado en el vientre horrendo del ave, y ha sido cercenado, como el pene de Kauyumari o los miembros de las figuras de papel recortado en los rituales otomíes.

\section{La sexualidad de Siete Guacamayo}

Las implicaciones sexuales del mito no son explícitas en el Popol Vuh. En esta, como en otras secciones, el texto k'iche' se caracteriza por la sutileza con la que presenta conceptos mitológicos profundos. Sin embargo, la comparación del relato con otras creencias y mitos relacionados permite entrever las connotaciones sexuales del mito de Siete Guacamayo. Estas se advierten especialmente en dos aspectos de su personalidad: su hábito de comer nances y su dolor de muelas.

Hoy en día, "comer fruta" es una metáfora para el acto sexual en Mesoamérica. Esta metáfora se relaciona con una distinción básica, documentada por Henne (1977) en el pueblo k'iche' de Chichicastenango, entre los alimentos verdaderos —esencialmente, el maíz-y las "comidas adicionales", que se comen sólo por gusto y no proveen sustento ni fuerza para el ser humano. Las frutas entran en esta última categoría. Tarn y Prechtel (1990) describen el uso de esta metáfora en Santiago Atitlán, tanto en la vida diaria como en contextos rituales. Como parte de los ritos de la Semana Santa, Mam se acuesta en medio de las frutas maduras que adornarán el monumento que se erige frente al altar mayor de la iglesia. Este rito es parte de todo un proceso que asegura la renovación del mundo y la fertilidad agrícola, y sus connotaciones sexuales son explícitas. Según Tarn y Prechtel (1990: 80), "la idea principal es que Mam está 'copulando' o “comiéndose' la fruta” (cf. Stanzione, 2003: 264-269; Christenson, 2001).

La metáfora de "comer fruta" reaparece en las narraciones sobre los héroes solares y lunares de Oaxaca y Guerrero, que le dan de comer una fruta a la mujer que han de violar (De Cicco y Horcasitas, 1962: 78; Hollenbach, 1977: 131, 144). En los relatos nahuas de la Costa del Golfo, el héroe del maíz arroja fruta desde un árbol a su madre o a su abuela, quienes en algunas versiones la comen con fruición. El episodio lleva implícita una agresión sexual (Chevalier y Buckles, 1995: 314-317; Chinchilla Mazariegos, s.f.).

Según el Popol Vuh, Siete Guacamayo subía todos los días a comer nances en un gran árbol; ésa era su comida. En forma sutil, este hábito lo pinta como un ser concupiscente, lujurioso, lo que seguramente está acorde con su vanidad. 
No es casual que Hunahpu le disparara con su cerbatana justo en el momento en que se ocupaba de "comer fruta". En sí, el disparo con cerbatana de Hunahpu se puede entender como otra metáfora sexual, pero aún más clara es la connotación sexual del dolor de muelas que Siete Guacamayo desarrolló a consecuencia del cerbatanazo.

Una encuesta sobre la etiología de la caries y el dolor dental, entre los q'eqchi's de San Pedro Carchá, contiene testimonios sobre el origen de estos males:

Un día mi mamá me dijo: Ese tu dolor de muelas no sólo es así. Yo le pregunté ¿Por qué? Ella me contestó, talvez te metiste con alguna mujer y talvez está enferma (embarazada)... (Ávila, 1977: 25).

También contaba un muchacho que no tiene mujer, pero talvez tuvo relación sexual con una mujer, y la mujer queda embarazada, talvez nadie lo sabe, pero al muchacho le empezó a doler la muela. Los padres sospechan luego lo que está pasando, porque es raro que un muchacho sufra dolor de muelas (Ávila, 1977: 27).

El dolor de muelas es un motivo recurrente en las narraciones mitológicas del área maya, y se asocia con las transgresiones sexuales. Una versión del mito del colibrí, recopilada en Senahú por Mario de la Cruz Torres (1978: 35) describe la magia amorosa del Sol, que trataba de acercarse a la Luna, una muchacha estrechamente vigilada por su padre. Para lograrlo, arrojó quince granos de maíz rojo sobre el techo de la casa, provocándole un fuerte dolor de muelas. La dolencia de la Luna solo se curó cuando la muchacha vio de nuevo al héroe, transformado en colibrí, y logró que su padre lo capturara por medio de un tiro de su cerbatana. Según otra versión del mito, fue el padre de la muchacha quien desarrolló un fuerte dolor de muelas cuando advirtió que su hija se había fugado (Ávila, 1977: 23).

El relato de Senahú también contiene un pasaje paralelo al mito de Siete Guacamayo en el Popol Vuh. La Luna — ahora mujer del Sol- fue raptada por el señor de $|\mathrm{X}|$ balba $[$ sic $]$. El héroe se valió del gusano de los dientes para causarle dolor de muelas al monstruo y, haciéndose pasar por médico, logró adormecerlo y liberar a su mujer. En todos estos relatos, el dolor de muelas se asocia con una transgresión sexual, un romance ilícito o un rapto. La vieja de la mitología ch'orti', que perdió los dientes al morder una mano de moler, también era un ser concupiscente. Su amante era un gigante o un danto, a quien le daba toda la comida que el héroe llevaba a la casa (Fought, 1989; Dary, 1986). Su destino recuerda al de las ogresas, poseedoras de vaginas dentadas, cuyos dientes fueron finalmente removidos por los héroes con un pene de piedra u otro material duro.

Este fue el castigo final de Siete Guacamayo, que se enorgullecía de sus dientes, "piedras de jade, tan brillantes como la faz del cielo" (Christenson, 2003: 92). Haciéndose pasar por curanderos que sabían sacar el gusano de los dientes, Hunahpu y Xbalanque extrajeron los de Siete Guacamayo, que sufría un fuerte dolor ocasionado por el cerbatanazo de Hunahpu. Con esto, su brillo decayó y ya no tuvo la apariencia de un señor. Los héroes completaron su labor sacándole 
los ojos - como aconteció a los monstruos solares en otras narraciones- y finalmente murió.

\section{Chimalmat}

La remoción final de los dientes de Siete Guacamayo es una reminiscencia del mito de la vagina dentada, pero ¿cómo encaja con la identidad masculina del personaje en el Popol Vuh? Siete Guacamayo es varón, y el texto k'iche' indica el nombre de su esposa, Chimalmat, la madre de Zipacna y Cabracan. Ella puede ser clave para entender la relación de Siete Guacamayo con los seres que poseen una vagina dentada en los mitos mesoamericanos.

Chimalmat no protagoniza hechos sobresalientes en el Popol Vuh. Sólo está en la casa cuando Siete Guacamayo llega sosteniendo su quijada herida, y luego muere junto con él, sin que se explique por qué. Sin embargo, su nombre es revelador. Se trata de una variante de un nombre nahua que, en la mitología azteca, corresponde a Chimalman, la madre de Quetzalcóatl. Según la Leyenda de los Soles, Chimalman se presentó desnuda ante Mixcoatl, quien le disparó sus flechas repetidamente, sin acertar. Chimalman se escondió en una cueva o una barranca y luego se presentó otra vez ante Mixcoatl, mostrándole su vulva. De nuevo, Mixcoatl le lanzó flechas sin acertar, pues un dardo pasaba sobre ella, otro a su lado, otro lo agarraba con la mano y el último pasaba entre sus piernas. Finalmente, el héroe logró acostarse con ella, preñándola (Bierhorst, 1998: 153).

La forma violenta en que Mixcoatl debe subyugar a Chimalman, su refugio en una cueva o barranca - esto es, en el interior de la tierra - y la manera en que expone sus genitales ante el héroe, encuentran una situación paralela en las ogresas, muchas veces asociadas con la tierra, que atraen a los héroes para luego devorarlos con su vagina dentada. En la Leyenda de los Soles, los encuentros de Chimalman y Mixcoatl van precedidos por un pasaje paralelo, en el que dos héroes deben vencer a los seres monstruosos que se les presentan con forma femenina. Los cazadores, Xiuhnel y Mimich, perseguían a dos venados de dos cabezas, que habían bajado del cielo. Por la noche, los venados se transformaron en mujeres que se presentaron ante sus perseguidores, invitándolos a comer y beber con ellas. Xiuhnel sucumbió a la invitación y fue devorado. Mimich resistió, y logró escapar tirándose en una fogata. La ogresa lo persiguió toda la noche, hasta el medio día, cuando cayó sobre una biznaga. Allí, el héroe logró asaetear a la ogresa, matándola. A continuación, la Leyenda se refiere a ella con el nombre de Itzpapalotl, y a su vencedor con el nombre de Mixcoatl (Bierhorst, 1998: 151-152).

Carr y Gingerich (1983; Gingerich, 1988: 218) han analizado este mito como una manifestación de las creencias en seres con vagina dentada, y argumentan que estas creencias se manifestaban fuertemente en la religión azteca, en el culto de la diosa Cihuacoatl Quilaztli. Esta diosa voraz, que exigía constantes sacrificios de cautivos de guerra, también recibía el nombre de tzitzimicihuatl. 


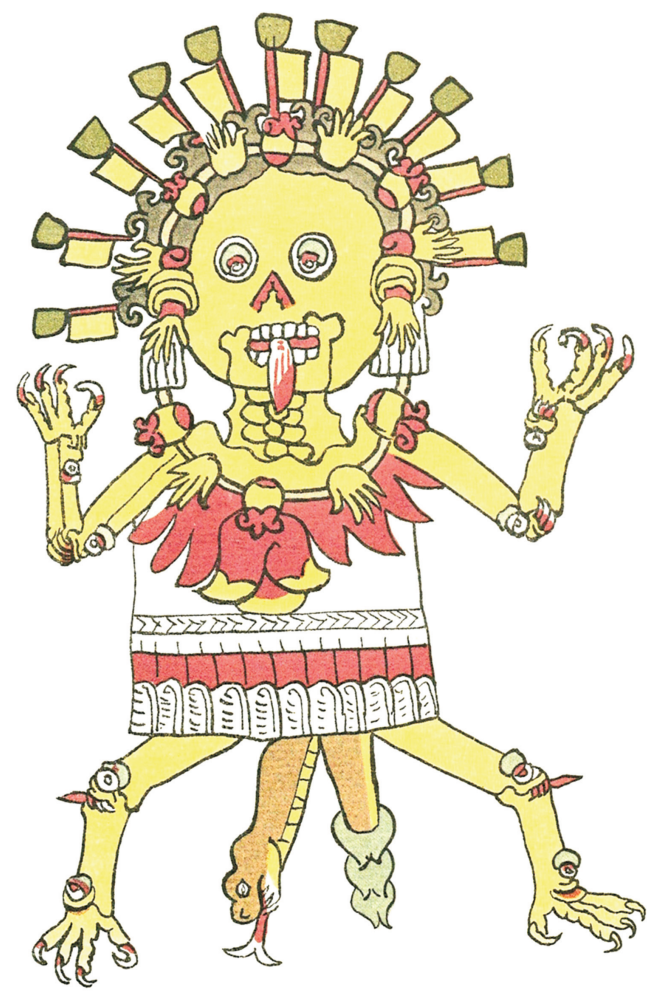

Figura 10. Tzitzimitl (Çiçimitl), con una serpiente cascabel en la región genital. Códice Magliabechiano, folio 76r. Según Zelia Nuttall (1982, lámina 64)

Carmen Aguilera (2003) la considera como regente de las tzitzimime, las mujeres horrendas, asociadas con las estrellas, que tenían el poder de traer lluvia, pero a la vez eran temidas como destructoras potenciales de la humanidad ( $c f$. Klein, 2000). Una lámina del Códice Magliabechiano (figura 10) representa a una tzitzimitl con una serpiente cascabel entre las piernas, como las ogresas de los relatos zoques y mixtecas, que tienen culebras en los genitales.

Chimalman pertenece a este complejo de diosas y también recuerda a las ogresas con vagina dentada de las narraciones contemporáneas. Es sugestiva la manera en que intentó atraer a Mixcoatl, exhibiendo sus genitales, y la manera en que este logró poseerla, tirándole flechas, que puede estar relacionada con la remoción de los dientes vaginales por medio de un instrumento duro. Heyden (1974: 7) considera a las flechas de Mixcoatl como símbolos fálicos (cf. Chinchilla Mazariegos, s.f.).

Las relaciones entre Chimalman y Cihuacoatl Quilaztli son múltiples. En el "Canto de Cihuacoatl", registrado por Sahagún, esta diosa clama por su príncipe, 
Mixcoatl, usando un lenguaje rico en alusiones sexuales. Con esto, parece tomar el papel que corresponde a Chimalman en la Leyenda de los Soles (Gingerich, 1988: 229). Por su parte, la Leyenda también afirma que Chimalman murió durante el parto, y Quetzalcóatl fue criado por Quilaztli, Cihuacoatl (Bierhorst, 1998: 153). En esta versión, Cihuacoatl toma el papel de la vieja que recogió y crió al héroe o héroes huérfanos, tema que se repite en numerosos mitos mesoamericanos. Con frecuencia, esta vieja comparte la voracidad sexual de los seres con vagina dentada y, en la mitología ch'orti', termina con los dientes quebrados.

El paralelismo se refuerza al considerar que las ogresas de la mitología azteca también adoptan figura de aves. Cihuacoatl se aparecía con forma de águila, y uno de sus nombres era Cuauhcihuatl, “mujer águila” (Aguilera, 2003: 94). La ogresa que persiguió a Mimich en la Leyenda de los Soles resulta ser otro ser volátil: Itzpapalotl, "mariposa de obsidiana”. La hora de su muerte, a mediodía, la asocia con los pájaros monstruosos de los mitos contemporáneos, que son destruidos por los héroes también a mediodía o al amanecer, en clara relación con el curso solar.

A pesar de que el Popol Vuh da pocos detalles sobre ella, el nombre de la esposa de Siete Guacamayo sugiere una conexión con Chimalman, Itzpapalotl, Cihuacoatl Quilaztli y las tzitzimime de la mitología azteca. Como manifestación de las mujeres monstruosas de la mitología mesoamericana, Chimalmat complementa la figura de Siete Guacamayo en el Popol Vuh, y quizás sea reminiscencia de las versiones antiguas del mito, en las que el gran pájaro solar poseía una vagina dentada. No es casual que Chimalmat muera al mismo tiempo que su marido; ella pareciera ser el aspecto femenino de Siete Guacamayo, parte inseparable de él.

\section{Observaciones finales}

A la luz de estas interpretaciones, las figuras de Siete Guacamayo y Chimalmat en el Popol Vuh se pueden entender como aspectos de un ser dual, que incorpora elementos masculinos y femeninos. La dualidad de género es una cualidad reconocida en la religión mesoamericana, que de acuerdo con la definición de Klein (2001: 186) se refiere a "entidades que incorporan simultáneamente en sí mismas un aspecto enteramente masculino y uno enteramente femenino. Estas entidades son frecuentemente descritas en los textos coloniales como parejas de esposos". En la religión azteca, Klein cita como ejemplos a la pareja creadora formada por Oxomoco y Cipactonal, y a la deidad creadora Ometeotl, que incorpora aspectos masculinos y femeninos bajo los nombres de Ometecuhtli y Omecihuatl. Hasta el presente, los individuos altamente venerados en muchas comunidades mesoamericanas, cualquiera que sea su género, suelen ser caracterizados en términos de ambos, como "padres-madres" (Klein, 2001: 188-189).

En la narrativa del Popol Vuh, Siete Guacamayo y Chimalmat son personas distintas pero que actúan al unísono, particularmente al momento de morir. Las 
representaciones de la Estela 25 de Izapa y los estucos del juego de pelota de Copán, claramente relacionadas con este mito, demuestran que, desde tiempos muy antiguos, el pájaro monstruoso de la mitología maya incorporaba un rasgo esencialmente femenino: la vagina dentada, con forma de cabeza de serpiente. Cabe preguntarse si este pájaro se consideraba enteramente femenino o si, como en el Popol Vuh, era un ser dual en términos de género.

La dualidad de género de Siete Guacamayo se relaciona con otra contradicción aparente en las figuras de los grandes pájaros con vagina dentada del arte prehispánico. Como lo ha enfatizado Báez-Jorge (2008), la vagina dentada suele ser característica de seres asociados con la tierra y con los fenómenos telúricos. Por otra parte, también se ha señalado cómo los seres que la poseen se relacionan en formas complejas con los grandes pájaros de las narraciones mitológicas, cuyo simbolismo solar los sitúa en un plano celestial. En su estudio sobre Cihuacoatl, Carmen Aguilera (2003) confrontó una disyuntiva similar, al encontrar que esta diosa, generalmente identificada con la agricultura y la tierra, tenía fuertes connotaciones celestiales.

Desde esta perspectiva, Siete Guacamayo y Chimalmat personifican, a la vez, fuerzas celestiales y terrestres. La dualidad se pone de manifiesto en el doble castigo de Siete Guacamayo: la extracción de sus ojos y sus dientes. La extracción de los ojos - tan importante en el Popol Vuh como en los relatos contemporáneos- fue indispensable para el advenimiento del Sol y la Luna. La extracción de los dientes alude al destino de las ogresas telúricas, cuya sexualidad destructiva debió refrenarse en la misma forma.

La derrota y muerte de Siete Guacamayo pareciera ser el punto culminante del mito en el Popol Vuh. Seguramente, este era el resultado final de la confrontación entre el héroe y el monstruo, desde tiempos antiguos. Sin embargo, las representaciones del periodo prehispánico no enfatizan el episodio final, sino el momento en que el gran pájaro arrancó el brazo del héroe. La connotación sexual del mito es clara en la Estela 25 de Izapa y los estucos del juego de pelota de Copán, donde el brazo del héroe aparece en la vagina dentada del monstruo. Estas representaciones, entre las más antiguas que conocemos, concentran su atención en la agresión sexual del ave desaforada, que personifica las fuerzas vitales en su forma más elemental. 


\section{BIBLIOGRAFÍA}

Aguilera, Carmen

2003 "Cihuacoatl: Celestial or Terrestrial”, Latin American Indian Literatures Journal 19 (1): 92-108.

Arias, Jacinto

1990 San Pedro Chenalhó: algo de su historia, cuentos y costumbres. Tuxtla Gutiérrez: Instituto Chiapaneco de Cultura.

Ávila, César Augusto

1977 “El Xul-E’. Creencias populares sobre la etiología de la caries y del dolor dental en grupos de indígenas kekchies”, Guatemala Indígena, 12 (1-2): 4-51.

Báez-Jorge, Félix

1983 "La cosmovisión de los zoques de Chiapas (reflexiones sobre su pasado y presente)", Antropología e Historia de los Mixe-Zoques y Mayas. Homenaje a Frans Blom, L. Ochoa y T. A. Lee, Jr. (eds.), pp. 383-412. México: Universidad Nacional Autónoma de México/Brigham Young University.

1990 "Las seductoras macabras (imágenes numinosas de la sexualidad femenina en Mesoamérica)", La Palabra y el Hombre: Revista de la Universidad Veracruzana, 73: 5-28.

1996 "Kauymáli y las vaginas dentadas (aproximación a la mitología huichola desde la perspectiva de un héroe civilizatorio)", La Palabra y el Hombre: Revista de la Universidad Veracruzana, 100: 101-119.

2008 El lugar de la captura (simbolismo de la vagina telúrica en la cosmovisión mesoamericana). México: Gobierno del Estado de Veracruz.

Bartolomé, Miguel Alberto

1979 Narrativa y etnicidad entre los chatinos de Oaxaca. México: Instituto Nacional de Antropología e Historia.

Benítez, Fernando

1984 Los indios de México, t. II, 4a ed. México: Era.

Berezkin, Yuri E.

s.f. "Amerindian Mythology with Parallels in the Old World". <http://ruthenia. ru/folklore/berezkin/eng/031_8.htm>. [Consultada el 5 de marzo de 2009.]

Bierhorst, John (ed.)

1998 History and Mythology of the Aztecs: The Codex Chimalpopoca. Tucson, Arizona: The University of Arizona Press.

Boege, Ekart

1984 "Vida Estatal, Mito e Historia entre los Mazatecos Actuales: Héroes, Aguilas y Comehombres", Investigaciones Recientes en el Area Maya: XVII Mesa Redon$d a$, tomo III, pp. 429-437. México: Sociedad Mexicana de Antropología. 
Carr, Pat, y Willard Gingerich

1983 "The Vagina Dentata Motif in Nahuatl and Pueblo Mythic Narratives: A Comparative Study", Smoothing the Ground: Essays on Native American Oral Literature, B. Swann (ed.), pp. 187-203. Berkeley, California: University of California Press.

Carrasco, Pedro, y Roberto J. Weitlaner

1952 "El Sol y la Luna", Tlalocan, 3: 169-173.

Castellón Huerta, Blas Román

1987 "Mitos Cosmogónicos de los Nahuas Contemporáneos”, Mitos cosmogónicos del México indígena, J. Monjarás-Ruiz (ed.), pp. 177-205. México: Instituto Nacional de Antropología e Historia.

Chevalier, Jacques M., y Daniel Buckles

1995 A Land Without Gods: Processual Theory, Maldevelopment, and the Mexican Nahuas. Londres/Nueva Jersey: Zed Books.

Chinchilla Mazariegos, Oswaldo

s.f. "Of Birds and Insects: The Hummingbird Myth in Ancient Mesoamerica". En prensa.

Christenson, Allen J.

2001 Art and Society in a Highland Maya Community: The Altarpiece of Santiago Atitlán. Austin, Texas: University of Texas Press.

Christenson, Allen J. (editor)

2003 Popol Vuh: The Sacred Book of the Maya. Winchester, Inglaterra: O Books.

Clark, John E., y Ayax Moreno

2007 "Redrawing the Izapa Stelas", Archaeology, Art, and Ethnogenesis in Mesoamerican Prehistory: Papers in Honor of Gareth W. Lowe, L. S. Lowe y M. E. Pye (eds.), pp. 277-319. Provo, Utah: Brigham Young University (Papers of the New World Archaeological Foundation, 68).

Dary, Claudia

1986 Estudio antropológico de la literatura oral en prosa del oriente de Guatemala. Universidad de San Carlos de Guatemala, Guatemala: Editorial Universitaria.

De Cicco, Gabriel, y Fernando Horcasitas

1962 "Los Cuates: un mito chatino", Tlalocan, 4 (1): 74-79.

De la Cruz Torres, Mario Enrique

1978 Rubelpec: cuentos y leyendas de Senahú, Alta Verapaz. Guatemala: Editorial del Ejército.

Fash, William L.

1998 "Dynastic architectural programs: Intention and design in Classic Maya 
buildings at Copan and other sites", Function and meaning in Classic Maya architecture, S. D. Houston (ed.), pp. 222-270. Washington, D. C.: Dumbarton Oaks.

Fash, William L. y Barbara Fash

1996 "Building a World-View: Visual Communication in Classic Maya Architecture", Res: Anthropology and Aesthetics 29/30: 127-147.

2000 "Teotihuacan and the Maya: A Classic Heritage", Mesoamerica's Classic Heritage: From Teotihuacan to the Great Aztec Temple, D. Carrasco, L. Jones y S. Sessions (eds.), pp. 433-463. Niwot, Colorado: University Press of Colorado.

Fought, John

1989 "Kumix, the Ch'orti' Hero", General and Amerindian Ethnolinguistics, in Remembrance of Stanley Newman, M. Ritchie Key y H. M. Hoenigswald (eds.), pp. 461-468. Berlín: Mouton de Gruyter.

Galinier, Jacques

1984 "L'Homme Sans Pied: Métaphores de la Castration et Imaginaire en Mésoamérique", L'Homme 24 (2): 41-58.

1990a "El depredador celeste: notas acerca del sacrificio entre los mazahuas", Anales de Antropología, 27: 251-267.

1990b La mitad del mundo: cuerpo y cosmos en los rituales otomíes. México: Universidad Nacional Autónoma de México/Centro de Estudios Mexicanos y Centroamericanos/Instituto Nacional Indigenista.

2001 "Una mirada detrás del telón: rituales y cosmovisión entre los otomíes orientales", Cosmovisión, ritual e identidad de los pueblos indígenas de México, J. Broda y F. Báez-Jorge (eds.), pp. 453-484. México: Consejo Nacional para la Cultura y las Artes y Fondo de Cultura Económica.

Gingerich, Willard

1988 “Three Nahuatl Hymns", Mexican Studies/Estudios Mexicanos, 4 (2): 191-244.

Girard, Rafael

$1972 \quad$ Esoterismo en el Popol Vuh, 3a ed. México: Editores Mexicanos Unidos.

Graulich, Michel

1997 Myths of Ancient Mexico. Norman, Oklahoma: University of Oklahoma Press.

Grazioso Sierra, Liwy

2002 "El Nuevo Rostro del Personaje en la Estela 25 de Izapa, Chiapas", Incidents of Archaeology in Central America and Yucatan: Essays in Honor of Edwin M. Shook, M. Love, M. P. Hatch y H. L. Escobedo (eds.), pp. 233-250. Lanham, Maryland: University Press of America.

Guernsey, Julia

2006 Ritual and Power in Stone: The Performance of Rulership in Mesoamerican Izapan Style Art. Austin, Texas: University of Texas Press. 
Guiteras Holmes, Calixta

1996 Los peligros del alma: visión del mundo de un tzotzil. México: Fondo de Cultura Económica,.

Gutiérrez del Ángel, Arturo

2007 "Cosmovisión y mitología en el Gran Nayar", Relatos ocultos entre la niebla y el tiempo: selección de mitos y estudios, B. R. Castellón Huerta (ed.), pp. 51122. México: Instituto Nacional de Antropología e Historia.

Henne, Marilyn G.

1977 "Quiche Food: Its Cognitive Structure in Chichicastenango, Guatemala", Cognitive Studies in Southern Mesoamerica, H. L. Neuenswander y D. E. Arnold (eds.), pp. 67-92. Dallas, Texas: Summer Institute of Linguistics.

Heyden, Doris

1974 "La Diosa Madre: Itzpapalotl”, Boletín del Instituto Nacional de Antropología e Historia, época II, 11: 3-14.

Hollenbach, Elena E.

1977 "El origen del sol y de la luna: cuatro versiones en el trique de Copala", Tlalocan, 7: 123-170.

Hoogshagen, Searle

1971 "La creación del sol y la luna según los mixes de Coatlán, Oaxaca”, Tlalocan, 6 (4): 337-346.

Jäcklein, Klaus

1974 Un pueblo popoloca. México: Instituto Nacional Indigenista.

Klein, Cecelia F.

2000 "The Devil under the Skirt: An Iconographic Inquiry into the Prehispanic Nature of the Tzitzimime", Ancient Mesoamerica, 11: 1-26.

2001 "None of the Above: Gender Ambiguity in Nahua Ideology", Gender in Prehispanic America, C. F. Klein (ed.), pp. 183-253. Washington, D. C.: Dumbarton Oaks.

Krickeberg, Walter

1971 Mitos y leyendas de los aztecas, incas, mayas y muiscas. México: Fondo de Cultura Económica.

Lipp, Frank

1991 The Mixe of Oaxaca: Religion, Ritual, and Healing. Austin, Texas: University of Texas Press.

Lizana, Bernardo de

1988 Historia de Yucatán. F. Jiménez Villalba (ed.). Madrid: Historia 16. 
López García, Julián

2002 "Restricciones culturales en la alimentación de los mayas-chortis y ladinos del oriente de Guatemala". Tesis de doctorado, Madrid: Universidad Complutense < http://www.ucm.es/BUCM/tesis/19911996/H/0/AH0021201.pdf.>. [Consultada el 3 de enero de 2009.]

Lowe, Gareth W.

1982 "Izapa Religion, Cosmology, and Ritual", Izapa: An Introduction to the Ruins and Monuments, G. W. Lowe, T. A. Lee y E. Martínez Espinosa (eds.), pp. 269306. Provo, Utah: Brigham Young University

Lupo, Alessandro

2002 "El vientre que nutre y devora: representaciones de la tierra en la cosmología de los huaves del Istmo de Tehuantepec", Anuario del Centro de Estudios Superiores de México y Centro América. < http://www.articlearchives. com/1076495-1.html>. [Consultada el 5 de marzo de 2009.]

Malotki, Ekkehart

1983 "The Story of the 'Tsimonmamant' or Jimson Weed Girls: A Hopi Narrative Featuring the Motif of the Vagina Dentata”, Smoothing the Ground: Essays on Native American Oral Literature, B. Swann (ed.), pp. 204-220. Berkeley, California: University of California Press.

Mendelson, E. Michael

1965 Los Escándalos de Maximón. Guatemala: Seminario de Integración Social Guatemalteca.

Miller, Walter S.

1956 Cuentos mixes. México: Instituto Nacional Indigenista.

Millán, Saúl

2007 El cuerpo de la nube: jerarquía y simbolismo ritual en la cosmovisión de un pueblo huave. México: Instituto Nacional de Antropología e Historia.

Monaghan, John

1995 The Covenants with Earth and Rain: Exchange, Sacrifice, and Revelation in Mixtec Society. Norman, Oklahoma: University of Oklahoma Press.

Neurath, Johannes

2004 "El doble personaje del planeta venus en las religiones indígenas del Gran Nayar: mitología, ritual agrícola y sacrificio”, Journal de la Societé des Américanistes, 90 (1): 93-118.

Norman, V. Garth

1973 Izapa Sculpture, Part 1: Album. Provo, Utah: Brigham Young University (Papers of the New World Archaeological Foundation, 30).

1976 Izapa Sculpture, Part 2: Text. Provo, Utah: Brigham Young University (Papers of the New World Archaeological Foundation, 30). 
Nuttall, Zelia

1982 "The book of the life of the ancient Mexicans, containing and account of their rites and superstitions, Part I, Introduction and Facsimile. Reproducción de la edición de 1903”, Elizabeth Hill Boone, The Codex Magliabechiano and the lost prototype of the Magliabechiano group. Berkeley, California: University of California Press.

Ochoa Peralta, María Angela

2000 "Las Aventuras de Dhipaak o dos facetas del sacrificio en la mitología de los teenek (huastecos)", Dimensión Antropológica, 20. < http://www.dimensionantropologica.inah.gob.mx $>$. [Consultada el 26 de marzo de 2007.]

Oropeza Escobar, Minerva

2007 "Mitos cosmogónicos de las culturas indígenas de Veracruz", Relatos ocultos en la niebla y el tiempo: Selección de mitos y estudios, B. R. Castellón Huerta (ed.), pp. 163-259. México: Instituto Nacional de Antropología e Historia.

Parsons, Elsie Clews

1936 Mitla, Town of the Souls, and Other Zapoteco-Speaking Pueblos of Oaxaca, Mexico. Chicago: The University of Chicago Press.

Portal, María Ana

1986 Cuentos y mitos en una zona mazateca. México: Instituto Nacional de Antropología e Historia.

Redfield, Robert

1946 “Notes on San Antonio Palopó”. University of Chicago Microfilm Collection, 4.

Sahlins, Marshall

1987 Islands of History. Chicago: The University of Chicago Press.

Stanzione, Vincent

2003 Rituals of Sacrifice: Walking the Face of the Earth on the Sacred Path of the Sun. A Journey through the Tz'utujil Maya World of Santiago Atitlán. Albuquerque, Nuevo Mexico: University of New Mexico Press.

Tarn, Nathaniel, y Martin Prechtel

1990 “'Comiéndose la fruta': metáforas sexuales e iniciaciones en Santiago Atitlán”, Mesoamérica, 19: 73-82.

1997 Scandals in the House of Birds: Shamans and Priests in Lake Atitlán. Nueva York: Marsilio.

Taube, Karl A.

1992 The Major Gods of Ancient Yucatan. Washington, D. C.: Dumbarton Oaks.

2005 "Representaciones del paraíso en el arte cerámico del Clásico Temprano de Escuintla, Guatemala", Iconografía y Escritura Teotihuacana en la Costa Sur de Guatemala y Chiapas, O. Chinchilla Mazariegos y B. Arroyo (eds.), pp. 35-54. Guatemala: Asociación Tikal (U Tz’ib, Serie Reportes, vol. 1, 5). 
Taube, Karl A.

2006 "Climbing Flower Mountain: Concepts of Resurrection and the Afterlife at Teotihuacan”, Arqueología e Historia del Centro de México: Homenaje a Eduardo Matos Moctezuma, L. López Luján, D. Carrasco y L. Cué (eds.), pp. 153-170. México: Instituto Nacional de Antropología e Historia.

Torres Cisneros, Gustavo

2007 "Los mitos mixes de la creación", Relatos ocultos en la niebla y el tiempo: selección de mitos y estudios, B. R. Castellón Huerta (ed.), pp. 261-395. México: Instituto Nacional de Antropología e Historia.

Van der Loo, Peter L.

2002 "Ritual and Myth in Tlapanec Life", Native Religions and Cultures of Central and South America, L. E. Sullivan (ed.), pp. 67-92. Nueva York: The Continuum International Publishing Group.

Villela Flores, Samuel

2008 "De gemelos, culebras y tesmósforos: mitología en Guerrero", Oxtotitlán, Itinerancias Antropológicas, 2: 5-11 <http://antropologia.uaguerrero.net/archivos/oxtotitlan-febrero-2008.pdf > . [Consultada el 30 de octubre de 2009.]

Weitlaner, Roberto J.

1981 Relatos, mitos y leyendas de la Chinantla. México: Instituto Nacional Indigenista.

Weitlaner, Roberto J. y Carlo Antonio Castro

1973 Usila, morada de colibríes. México: Museo Nacional de Antropología (Papeles de la Chinantla, 11).

Zaragoza, Nicolás

2007 "Metztli Azul, Jueves 15 de febrero de 2007. El Mito de los Gemelos (Sol y Luna)... Oaxaca. Versión recopilada en Ojitlán, Oaxaca, en 1972, narrada por Nicolás Zaragoza < http://metztliazul.blogspot.com/2006/12/el-mito-delos-gemelos-sol-y.html > . [Consultada el 30 de julio de 2008.]

Zingg, Robert M.

1982 Los huicholes, una tribu de artistas. México: Instituto Nacional Indigenista, 2 tomos. 